\title{
SiC Bipolar Devices for High Power and Integrated Drivers
}

\author{
M. Östling, R. Ghandi, B. Buono, L. Lanni, B.G. Malm and C-M. Zetterling \\ KTH Royal Institute of Technology, School of ICT, Electrum 229, SE 16440 Kista, Sweden
}

\begin{abstract}
Silicon carbide (SiC) semiconductor devices for high power applications are now commercially available as discrete devices. The first SiC device to reach the market was the unipolar Schottky diode. Active switching devices such as bipolar junction transistors (BJTs), field effect transistors (JFETs and MOSFETs) are now being offered in the voltage range up to $1.2 \mathrm{kV}$. SiC material quality and epitaxy processes have greatly improved and degradation free $100 \mathrm{~mm}$ wafers are readily available, which has removed one obstacle for the introduction of bipolar devices. The SiC wafer roadmap looks very favorable as volume production takes off. Other advantages of $\mathrm{SiC}$ are the possibility of high temperature operation $\left(>300{ }^{\circ} \mathrm{C}\right)$ and in radiation hard environments, which could offer considerable system advantages. Thanks to the mature SiC process technology, low-power integrated circuits are now also viable. Such circuits could find use in integrated drivers operating at elevated temperatures.

Index Terms - Silicon Carbide bipolar process technology, bipolar physics and simulation, power devices, analog/digital circuits, integrated drivers, high temperature, radiation hardness.
\end{abstract}

\section{INTRODUCTION}

The key figure of merit for power switches is the specific on-resistance $R_{\text {on,sp. This parameter tells }}$ directly how much resistive loss a device generates in the forward conduction mode. Several of the published device data for diodes, JFETs and BJTs are very close to the theoretical limit. For MOSFETs the channel resistance in $\mathrm{SiC}$ dominates because of the low channel mobility, and experimental data therefore suffers. Although BJTs would be expected to perform better than the unipolar limit, high injection is seldom achieved. Therefore high injection devices such as IGBTs and GTOs are explored for the highest breakdown voltages.

\section{SiC Rectifiers}

In power circuits, rectifiers are continuously switched between the ON and OFF states. These devices are also required to demonstrate low power loss switching characteristics especially for high frequency applications. The main power rectifiers are PiN diodes and Schottky diodes. The advent of SiC with one order of magnitude higher critical electric field has made it possible to implement thinner drift layer with higher doping and lower ON-resistance compared to Si. Also these devices have demonstrated higher temperature capability compared to $\mathrm{Si}$ based devices. In this section, structure, characteristics and challenges of these devices are shortly discussed and recent breakthroughs of $\mathrm{SiC}$ rectifiers are highlighted.
PiN Rectifiers

Optimum performance of the Si PiN diode is limited by the maximum switching frequency and a trade-off between forward voltage drop and switching speed is needed. 4H-SiC PiN diodes can provide higher switching speed and lower voltage drop compared to Si PiN diodes because of a thinner drift layer. These diodes have also shown high-temperature operation that is desired in many high power applications. The main concern for fabrication of high voltage $4 \mathrm{H}-\mathrm{SiC}$ PiN diodes is high quality growth of a lowly doped thick epitaxial layer with high minority carrier lifetime for optimum conductivity modulation. However, the performance of the $\mathrm{SiC} \mathrm{PiN}$ diode can be degraded under forward voltage stress resulting in an increasing forward voltage drop. This phenomenon which is known as bipolar degradation is due to Shockley stacking faults (SSF) that originate from basal plane dislocations and this is discussed in more detail in the next sections. Table 1 summarizes recent reported high voltage $\mathrm{SiC} \mathrm{PiN}$ diodes in terms of breakdown voltage, ON-resistance and forward voltage drop at $100 \mathrm{Acm}^{-2}$.

Table 1: Recent reported high voltage 4H-SiC PiN diodes

\begin{tabular}{cccc}
\hline $\mathrm{V}_{\mathrm{br}}(\mathrm{kV})$ & $\begin{array}{c}\mathrm{R}_{\mathrm{ON}} \\
\left(\mathrm{m} \Omega \mathrm{cm}^{2}\right)\end{array}$ & $\begin{array}{c}\mathrm{V}_{\mathrm{F}} \\
\left(100 \mathrm{Acm}^{-2}\right.\end{array}$ & Ref. \\
\hline 3.3 & 1.7 & 3.3 & {$[1]$} \\
4.5 & 1.7 & 3.3 & {$[2]$} \\
6.5 & 34 & 3.4 & {$[3]$} \\
10 & 38 & 3.9 & {$[4]$} \\
$12-19$ & 65 & $4.4-7.5$ & {$[5]$} \\
\hline
\end{tabular}

\section{Schottky Barrier Diodes (SBD)}

High voltage $4 \mathrm{H}-\mathrm{SiC}$ SBDs have been introduced to the market since 2001. Compared to Si diodes, these rectifiers show faster switching due to the thinner drift layer at the expense of higher forward voltage drop across the junction. Therefore, SiC SBDs are interesting devices particularly when the switching power losses are dominant. At the moment, 300V/30A-1700V/25A SiC SBDs are commercially available and there is potential for fabrication of higher power rectifiers as the material quality improves further.

\section{JBS and MPS diodes}

To utilize the properties of the PiN diode and Schottky diodes, JBS and MPS have been introduced as monolithic combinations of both devices. Junction barrier controlled Schottky (JBS) is a Schottky diode with an integrated $\mathrm{P}^{+}-\mathrm{N}$ junction grid into the drift region. During reverse bias, the integrated $\mathrm{P}$ layer, 
extend the depletion layer, shield the Schottky barrier and reduce the leakage current compared to conventional Schottky rectifiers. Merged PiN/Schottky (MPS) rectifiers employ the same approach for combining two conventional rectifiers and act like JBS in the blocking mode. However, the integrated $\mathrm{P}^{+}$layers are forward biased at high current levels and inject high concentration of minority carriers into the lowly doped n-layer that results in conductivity modulation, thereby protecting the diode from overheating under surge current conditions. Due to the presence of Schottky contact, the total charge required for conductivity modulation is less compared to the PiN diode that results in better recovery during turn-off. SiC JBS diodes are regarded as an interesting candidate to replace SBDs in the relatively high voltage range. However material quality and process complexity are still the main concern for fabrication of these types of devices. Table 2 demonstrates recent reported JBS rectifiers in SiC.

Table 2: Recent reported high voltage 4H-SiC JBS diodes

\begin{tabular}{cccc}
\hline $\mathrm{V}_{\mathrm{br}}(\mathrm{kV})$ & $\mathrm{R}_{\mathrm{ON}}\left(\mathrm{m} \Omega \mathrm{cm}^{2}\right)$ & $\mathrm{V}_{\mathrm{F}}$ & Ref. \\
\hline 1.6 & 7.5 & $1.4 \mathrm{~V} @ 100 \mathrm{Acm}^{-2}$ & {$[6]$} \\
2.8 & 6.2 & $2 \mathrm{~V} @ 100 \mathrm{Acm}^{-2}$ & {$[7]$} \\
5 & 25.2 & $3.5 \mathrm{~V} @ 108 \mathrm{Acm}^{-2}$ & {$[8]$} \\
10 & 100 & $3.37 \mathrm{~V} @ 20 \mathrm{Acm}^{-2}$ & {$[9]$} \\
\hline
\end{tabular}

SiC BJTS

Silicon bipolar power transistors are available since 40 years. The potential of operating at relatively high current densities with low power loss and high voltage capability was regarded as the distinguishing features of high voltage power BJTs. For these switches, operation in the forward direction is beneficial for reaching low on-state loss since the two built-in pn-junctions cancel each other. Hence, the onstate loss is mostly dependent on the drift layer resistance and the substrate resistance. However, due to low current gain of power BJTs at typical operating current levels, they have been replaced with insulated gate bipolar transistors (IGBT) and power MOSFETs in many power electronics applications. Also, operation of Si power bipolar transistors is limited by two major destructive effects that are known as thermal runaway and second breakdown. The thermal runaway, in which the total current increases with a positive feedback mechanism, occurs at elevated temperatures. This phenomenon, can occur due to the positive temperature coefficient of the forward voltage drop in a Si BJTs, and is caused by an increasing carrier lifetime in the device at elevated temperatures. This leads to a higher carrier concentration, higher current density and even more local increase in the temperature which is escalated by an increase in the total current. Interesting properties of $\mathrm{SiC}$ as a wide band gap semiconductor and robustness to harsh environments has made it possible to consider the $\mathrm{SiC}$ BJTs as one candidate for high power applications due to its low power on-state loss and fast switching capability.

These devices show negative temperature coefficient of the current gain in which, the current gain of the device is significantly decreased at higher temperatures due to the activation of deep level acceptors in the base that limit the emitter injection efficiency. Also the specific ON-resistance of the device is increased at elevated temperatures due to the decreasing electron mobility which causes an increase in the resistance of the collector layer. These characteristics are desired for parallel connection of BJTs for high temperature applications. Moreover, the high critical field strength of $\mathrm{SiC}$ made it possible to use higher doping in the collector layer. For this reason second breakdown occurs at a very high current density which is well outside the normal operation area of the device [10]. The BJT is also extremely robust with high surge current capability, high temperature performance and high cosmic-ray radiation hardness.

A main design concern is to optimize the lowly doped collector epitaxy to accommodate the high reverse voltage but not to yield any additional series resistance. Ultimately, high injection devices will be needed. The most crucial optimization from a practical point today is to increase the current gain at application temperature [11-13]. Typically a current gain of 100 is desired when designing efficient drive circuitry. It is clear that an optimized surface passivation in the sensitive base-emitter surface region is very important for minimizing the base current recombination. Therefore in $4 \mathrm{H}-\mathrm{SiC}$ BJTs, thermal oxidation in $\mathrm{N}_{2} \mathrm{O}$ or post oxide anneal in $\mathrm{N}_{2} \mathrm{O}$ are used to form state-of-the-art surface passivation. An improved passivation layer in terms of lower interface state density can decrease surface recombination current at the exposed base surface and along base-emitter junction sidewall thus resulting in higher current gain. Recently, it has been shown that deposited oxides followed by optimized nitridation annealing can results in improved current gain of up to $\beta \sim 257$ in SiC BJTs [14].

\section{EDGE TERMINATION}

Normally, vertical power transistors apply mesa edges for isolation of the layers. At the mesa edges, and close to the surface of the device, the critical electric field can be increased due to the curvature of the electric field profile. Therefore junction termination has to be adopted to locally reduce the electric field. There are different junction termination techniques for $\mathrm{SiC} \mathrm{BJTs}$ that can be adopted singularly or in combination with each other. The most common technique for BJTs is an implanted Junction Termination Extension (JTE) in which the collector layer is locally implanted by p-dopants with lower doping than the base layer close to the base mesa. The other technique is field ring (guard ring) 
termination that includes implanting p-type field rings surrounding the entire base mesa. This technique can be combined with implanted JTE and called guard ring assisted JTE [15]. Another junction termination is mesa-etched JTE that requires etching of single or multiple zones in the implanted [16] or in the epitaxial p-base layer [17] close to the main isolation to the collector. All of these terminations should be designed in a way to achieve an accurate dose of charge that becomes completely depleted to the surface close to the desired breakdown voltage, thereby reducing the maximum electric field in the edge region. It was also shown that the passivation layer can provide effective oxide charge and this can affect the optimum doses of implanted dopants in the JTE area, resulting in reduced breakdown voltage. Therefore, modification of JTE implantation dose may be needed when applying new passivation layers to high voltage $\mathrm{SiC}$ devices [18]. Consequently, $2800 \mathrm{~V}$ large area $\left(3 \mathrm{~mm}^{2}\right)$ BJTs with a maximum $\mathrm{dc}$ current gain of 52 and $\mathrm{R}_{\mathrm{ON}}=6.8 \mathrm{~m} \Omega \mathrm{cm}^{2}$ was reported (Figure 1) [19].

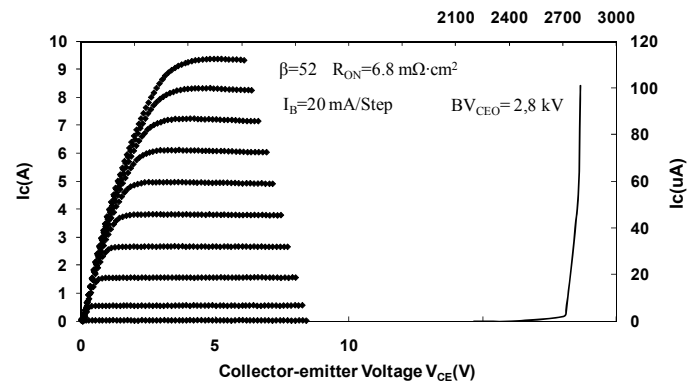

Figure 1: Room temperature IV characteristics of $3 \mathrm{~mm}^{2}$ BJT

\section{SWITCHING}

The switching characteristics of this device were investigated with a driver circuit that is schematically demonstrated in Figure 2. In this topology the passive network composed of a resistance $\mathrm{R} 2$ for $\mathrm{DC}$ biasing and a series connection of $\mathrm{R} 1$ and $\mathrm{C} 1$ for dynamic overshoot of the base current during turn on and off. A double pulse is fed to the gate driver of IXDN509 to ramp up the inductor current. The BJT acts as a switch for a $5 \mathrm{mH}$ inductive load with a $1200 \mathrm{~V} 8 \mathrm{~A}$ Schottky diode from Infineon (IDH08S120) as a freewheeling diode.

The turn-on and turn-off transients for $400 \mathrm{~V}$ switching are shown in Figure 3. The large area BJT shows a $V_{C E}$ fall time of 18 ns during turn-on and a $\mathrm{V}_{\mathrm{CE}}$ rise time of $10 \mathrm{~ns}$ during turn-off. The fast switching without the current tail shows the potential for significantly smaller power losses compared to a Si IGBT. For high frequency application, minimal conductivity modulation is desired for an efficient switching; however, for high voltage switches, the power BJT should demonstrate conductivity modulation in the saturation region for the lowest ON-resistance.

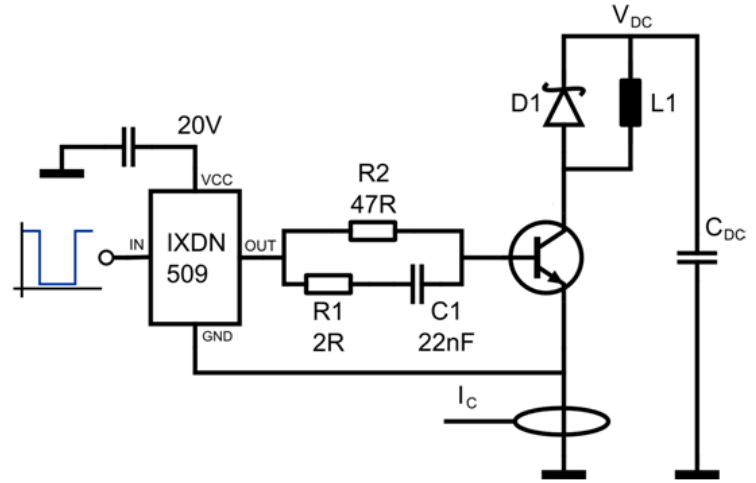

Figure 2: Schematic of the test circuit for switching high voltage BJT

a)

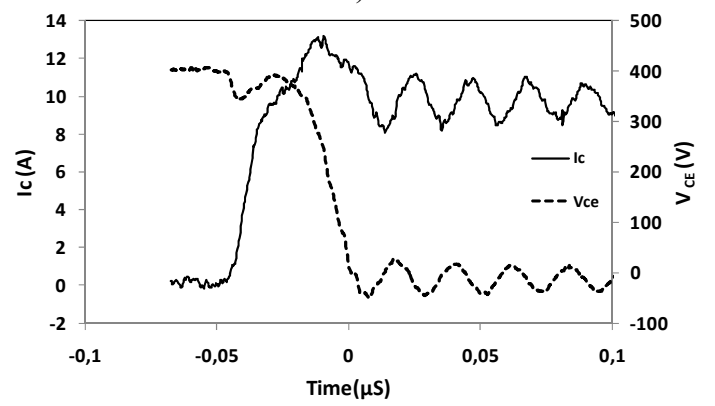

b)

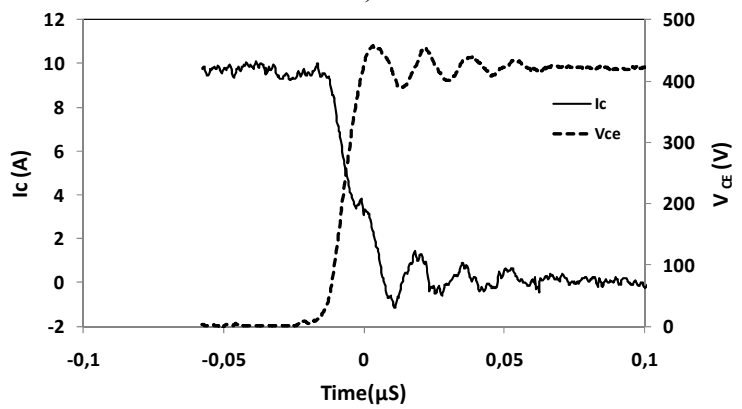

Figure 3: Transient characteristics of large area BJT for 400V switch during a) Turn-on and b) Turn-off

Table 3 summarizes the recent reported values for $4 \mathrm{H}-\mathrm{SiC}$ BJTs.

Table 3: Recent reported 4H-SiC BJTs

\begin{tabular}{cccc}
\hline $\mathrm{V}_{\mathrm{br}}(\mathrm{kV})$ & $\mathrm{R}_{\mathrm{ON}}\left(\mathrm{m} \Omega \mathrm{cm}^{2}\right)$ & Current Gain & Ref. \\
\hline 0.95 & 3.2 & 134 & {$[20]$} \\
1 & 2.9 & 33 & {$[21]$} \\
1.2 & 6.3 & 70 & {$[22]$} \\
1.2 & 5.2 & 60 & {$[23]$} \\
1.5 & 3.4 & 40 & {$[12]$} \\
1.6 & 5.1 & 70 & {$[24]$} \\
1.8 & 4.4 & 40 & {$[25]$} \\
2.2 & 4.5 & 35 & {$[12]$} \\
2.7 & 12 & 50 & {$[17]$} \\
2.8 & 4.5 & 55 & {$[19]$} \\
6 & 28 & 3 & {$[26]$} \\
9.2 & 49 & 7 & {$[27]$} \\
\hline
\end{tabular}


So far conductivity modulation, which is one potentially main advantage of bipolar devices compared to unipolar devices, has not been readily observed in $4 \mathrm{H}-\mathrm{SiC}$ BJTs. Low carrier lifetime which is due to the various defects in the $\mathrm{SiC}$ structure and also higher doping of the drift layer compared to $\mathrm{Si}$ power BJTs are factors explaining the absence of conductivity modulation. Therefore, optimum growth condition in terms of less defects and higher carrier life time not only improves the current gain but it can be advantageous also for achieving conductivity modulation.

\section{DEGRADATION}

The other challenge which is the main obstacle for commercialization of $4 \mathrm{H}-\mathrm{SiC}$ BJTs is degradation of the forward voltage drop $\left(\mathrm{V}_{\mathrm{CESAT}}\right)$ and degradation of the current gain, under forward bias stress at high current density. Like the PiN diodes, degradation of $\mathrm{V}_{\text {CESAT }}$ is mainly attributed to carrier trapping and recombination in the base and/or collector due to the SSFs. However, a current gain degradation mechanism with no significant decrease on the onresistance has been observed for BJTs on BPD-free substrate, and for small-area BJTs on standard substrates. The reason for this gain degradation is not clear and three possible mechanisms have been proposed:

1. an increase of the interface trap density along the $\mathrm{SiC} / \mathrm{SiO}_{2}$ interface

2. recombination enhanced defect generation in the base emitter region

3. small size stacking faults in the base-emitter region [28]

\section{DARLINGTON PAIR}

Increasing the current gain by two cascaded BJTs in a Darlington configuration is a potential solution for high power applications at the expense of a higher forward voltage drop. The optimally-designed Darlington can provide higher current gain $(\beta$ Darlington $=\beta_{\text {(Driver BJT) }} \times \beta_{\text {(Output BJT) }}$ ) compared to a single BJT along with high voltage blocking characteristics. Hybrid SiC Darlington transistors with $500 \mathrm{~V}$ and current gain of 430 [29] and $10 \mathrm{kV}$ with current gain of 440 [30] have been previously reported. However, monolithic Darlington design is preferred due to simpler design, better control in fabrication process and reproducibility. Recently Zhang et al. demonstrated a $10 \mathrm{kV}$ monolithic Darlington BJT with current gain of 1200 [31]. The dependence of the maximum current gain in a $4 \mathrm{H}-\mathrm{SiC} \mathrm{BJT}$ on the collector current, emphasizes the importance of the ratio between the area of the driver and the output BJTs. For the maximum current gain, the driver BJT should be designed in a way that it is not only biased for the maximum gain but also provides the required current for the highest gain to the output BJT. In [32] an implantation free monolithic Darlington with a maximum current gain of 2900 at room temperature is reported and it is shown that the high current gain is related to an optimum design for the ratio of the active area of the driver BJT to the output BJT (approximately 1:10). The forward characteristic of the Darlington transistor is shown in Figure 4.

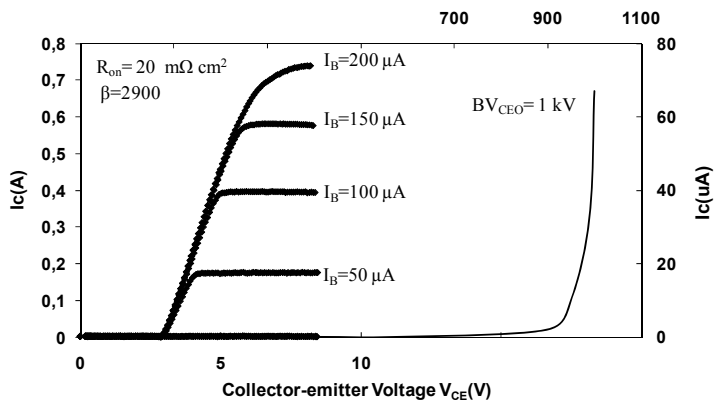

Figure 4: Room temperature I-V characteristics of the Darlington transistor [32].

Also, assemble and package a full power module based on $\mathrm{SiC}$ devices in order to take full advantage of the high potential of increasing power density is a very challenging issue. Several groups have demonstrated promising results that are summarized in [33] and references therein.

\section{EXTREME HIGH VOLTAGE - HIGH INJECTION DEVICES}

Devices for extremely high voltage $(>10 \mathrm{kV})$ require ultimate materials quality for two main reasons. Firstly, at these high voltages defects in the material will cause premature breakdown and secondly, in order to yield a reasonable low onresistance the devices must operate during high injection which also calls for high quality $\mathrm{SiC}$ wafers with a minimum basal plane dislocation density to achieve long minority carrier lifetimes.

Si IGBTs, as a commercially successful power device, replaced bipolar transistors in medium power applications that require high switching frequency and excellent on-state characteristics. However, performance of $\mathrm{Si}$ IGBTs are limited by high switching losses due to presence of minority carriers. High critical electric field as well as high temperature capability of $\mathrm{SiC}$ has urged different groups to consider fabrication of high voltage SiC IGBTs as a potential candidate for higher power applications [34]. N-channel IGBT which is composed of nchannel MOS and a PNP transistor is a preferred structure compared to p-channel IGBT due to the improved n-channel MOS process conditions with low interface states. However, the n-channel IGBT requires a p-type substrate. P-type substrates are not available in large dimensions and production volumes and they also introduce high resistance in series to the device. Recently $13 \mathrm{kV}, 22 \mathrm{~m} \Omega \mathrm{cm}^{2} \mathrm{n}$-IGBT have 
been reported [35]. This device shows conductivity modulation during forward conduction that corresponds to higher current capability compared to a $10 \mathrm{kV}$ SiC DMOSFET. High quality thick epitaxial growth with a long carrier life time is still a major challenge for development of SiC IGBTs.

$\mathrm{Si}$ GTOs suffer from large switching loss especially during turn-off due to the large current tails. The SiC GTO with high voltage capability is considered as an interesting device due to better thermal conductivity and larger breakdown field. However, the requirement of a large gate drive current for turn-off and also material quality are regarded as the main challenges of SiC GTO for high power applications. Recently a record large $1 \times 1 \mathrm{~cm}^{2}$ sized Gate Turn-Off (GTO) thyristor with a breakdown voltage of $9 \mathrm{kV}$ and a 1 ms current pulse of about $3 \mathrm{kA}$ has been demonstrated [36].

\section{INTEGRATED DRIVER CIRCUITS}

For a power switching system such as a motor drive, being able to operate the switches close to the motor will reduce the inductive losses. Low voltage high temperature electronics for drivers close to the switches will further reduce the system losses. There have been several demonstrations of $\mathrm{SiC}$ integrated circuits, such as the work on TTL by Singh et al. [37]. We have recently [38] demonstrated small-scale integration of emitter-coupled logic gates for these applications, as illustrated by the chip photo in Figure 5. Operation of logic gates has been verified up to $300{ }^{\circ} \mathrm{C}$, as shown in Figs. 6 and 7. The circuit is built in a low-voltage $\mathrm{SiC} \mathrm{BJT}$ process with a current gain of 45 at room temperature, $\left(25\right.$ at $\left.300{ }^{\circ} \mathrm{C}\right)$, and operates from a $15 \mathrm{~V}$ supply. Logic levels are clearly defined and results closely match simulations, based on preliminary SPICE models. Measured noise margins are stable from room temperature up to $300^{\circ} \mathrm{C}$ and are about $0.9 \mathrm{~V}$ for both $\mathrm{OR}$ and NOR output.

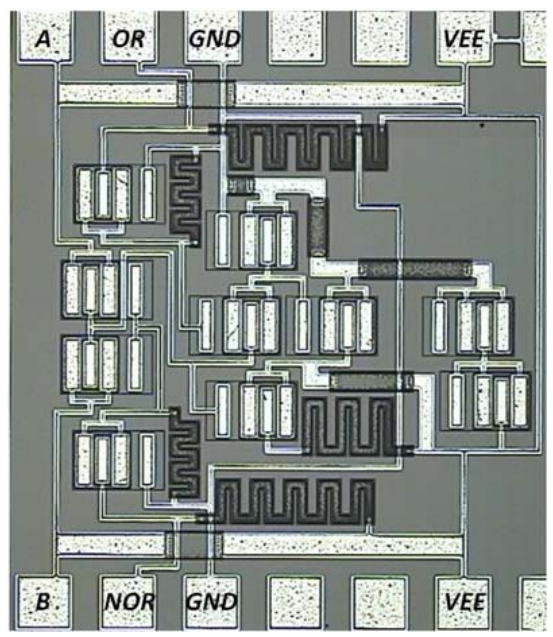

Figure 5: Chip photo of ECL OR/NOR gate in low-voltage SiC
BJT process

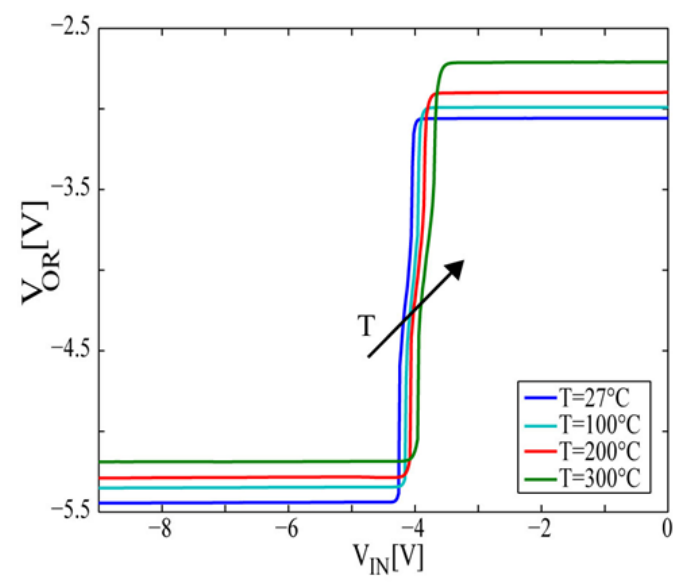

Figure 6: SiC intergrated ECL OR-NOR gate: OR output vs. temperature

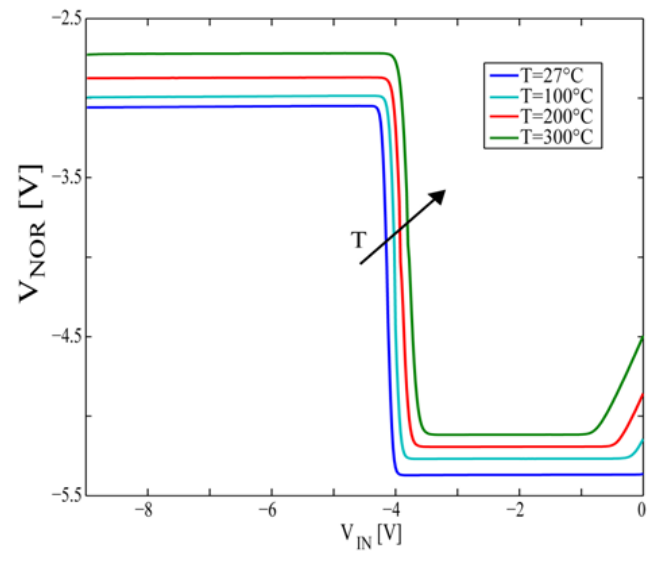

Figure 7: SiC integrated ECL OR-NOR gate: NOR output vs. temperature.

Further, the possibility of analog applications such as OP-amplifiers will be explored using the same process technology.

\section{COST ANALYSIS}

At present the cost per ampere is still too high for a massive breakthrough on the commercial massmarket for active high voltage switch devices in $\mathrm{SiC}$. However, the trend line and cost analysis of wafer substrates and epitaxial services show a very fast decrease. To date a substantial part of the total device cost is dependent on the wafer cost and it is likely that the price per ampere will meet the market demands of 10-20 US cents per ampere in just a few years.

\section{CONCLUSIONS}

Recent advantages in SiC wafer quality and device process technology, has prompted a renewed interest in bipolar devices. Several high voltage BJT 
demonstrators with optimized current gain $(\beta>100)$ and advanced termination structures for high blocking voltage have been demonstrated. Very low specific On-resistance $\left(<2.7 \mathrm{~m} \Omega \mathrm{cm}^{2}\right)$ have also been achieved for devices with $>1200 \mathrm{~V}$ breakdown voltage. SiC BJTs are also making their way into the area of integrated circuits for high-temperature applications. Recent progress for GTOs, and IGBT also indicates the potential for extremely high voltage $(>10 \mathrm{kV})$ devices.

\section{ACKNOWLEDGEMENT}

The authors acknowledge the research funding from the Swedish Energy Agency (STEM) and the Swedish Governmental Agency for Innovation Systems (VINNOVA).

\section{REFERENCES}

[1] P. Brosselard, N. Camara, J. Hassan, X. Jordà, P. Bergman, J. Montserrat, and J. Millán, "3.3 kV-10A 4H-SiC PiN diodes," Materials Science Forum, vol. 600-603, 2009, pp. 991-994.

[2] P. Brosselard, A. Perez-Tomas, J. Hassan, N.

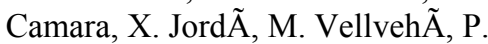
Godignon, J. MillÃ $i n$, and J.P. Bergman, "Low loss, large area $4.5 \mathrm{kV} 4 \mathrm{H}-\mathrm{SiC}$ PIN diodes with reduced forward voltage drift," Semiconductor Science and Technology, vol. 24, 2009 , p. 95004.

[3] D. Peters, W. Bartsch, and B. Thomas, "6.5 kV SiC PiN Diodes with Improved Forward Characteristics," Materials Science Forum, vol. 645-648, 2010, pp. 901-904.

[4] B.A. Hulla, J.J. Sumakeris, M.K. Das, J.T. Richmond, and J. Palmour, "20 A/10 kV 4HSiC PiN, Progress on the Development of 10 $\mathrm{kV} 4 \mathrm{H}-\mathrm{SiC}$ PiN Diodes for HighCurrent/High Voltage Power Handling Applications," Materials Science Forum, vol. 556-557, 2007, pp. 895-900.

[5] Y. Sugawara, D. Takayama, K. Asano, R. Singh, J. Palmour, and T. Hayashi, "12-19 kV $4 \mathrm{H}-\mathrm{SiC}$ pin diodes with low power loss," Power Semiconductor Devices and ICs, 2001. ISPSD '01. Proceedings of the 13th International Symposium on, 2001, pp. 27-30.
[6] T. Yamamoto, J. Kojima, T. Endo, E. Okuno, T. Sakakibara, and S. Onda, "1200-V JBS Diodes with Low Threshold Voltage and Low Leakage Current," Materials Science Forum, vol. 600-603, 2009, pp. 939-942.

[7] F. Dahlquist, J.O. Svedberg, C.M. Zetterling, M. Östling, B. Breitholtz, and H. Lendenmann, "A 2.8kV, 2V Forward Drop JBS Diode with Low Leakage," Materials Science Forum, vol. 338-342, 2000, pp. 11791182.

[8] J. Hu, L.X. Li, P. Alexandrov, and X. Wang, "5 kV, 9.5 A SiC JBS Diodes with Nonuniform Guard Ring Edge Termination for High Power Switching Application," Materials Science Forum, vol. 600-603, 2009, pp. 947-950.

[9] J.J. Sumakeris, M.J. O'Loughlin, Q. Zhang, J. Richmond, A. Powell, M. Paisley, V.

Tsvetkov, A. Hefner, A. Rivera, and B.A.

Hull, "Development of Large Area (up to 1.5 $\mathrm{cm} 2$ ) 4H-SiC $10 \mathrm{kV}$ Junction Barrier Schottky Rectifiers," Materials Science Forum, vol. 600-603, 2009, pp. 931-934.

[10] Y. Gao, A.Q. Huang, B. Chen, A.K. Agarwal, S. Krishnaswami, and C. Scozzie, "Analysis of SiC BJT RBSOA," IEEE International Symposium on Power Semiconductor Devices and IC's, 2006. ISPSD 2006., 2006, pp. 1-4.

[11] H. Miyake, T. Kimoto, and J. Suda, "Improvement of Current Gain in $4 \mathrm{H}-\mathrm{SiC}$ BJTs by Surface Passivation With Deposited Oxides Nitrided in $\mathrm{N} 2 \mathrm{O}$ or NO," IEEE Electron Device Letters, vol. 32, 2011, p. 285-287.

[12] M. Domeij, C. Zaring, A.O. Konstantinov, M. Nawaz, J.-O. Svedberg, K. Gumaelius, I. Keri, A. Lindgren, B. Hammarlund, M. Östling, and M. Reimark, "2 kV SiC BJTs with low VCESAT fast switching and shortcircuit capability," Materials Science Forum, vol. 645-6648, 2010, pp. 1033-1036.

[13] M. Östling, "Silicon Carbide Based Power Devices," 2010 IEEE International Electron Devices Meeting (IEDM), 2010, pp. 316-319. 
[14] H. Miyake, T. Kimoto, and J. Suda, "4H-SiC Bipolar Junction Transistors with Record Current Gains of 257 on ( 0001 ) and 335 on ( 000-1 )," Proceedings of the 23rd International Symposium on Power Semiconductor Devices \& IC's May 23-26, 2011 San Diego, CA, 2011, pp. 292-295.

[15] R. Perez, D. Tournier, A. Perez-Tomas, P. Godignon, N. Mestres, and J. Millan, "Planar edge termination design and technology considerations for $1.7-\mathrm{kV} 4 \mathrm{H}-\mathrm{SiC}$ PiN diodes," IEEE Trans. Electron Dev., vol. 52, 2005, pp. 2309-2316.

[16] X. Li, K. Tone, L. Fursin, J.H. Zhao, T. Burke, P. Alexandrov, M. Pan, and M. Weiner, "Multistep junction termination extension for $\mathrm{SiC}$ power devices," Electronics Letters, vol. 37, 2001, pp. 392-393.

[17] R. Ghandi, M. Domeij, B. Buono, C.-M. Zetterling, and M. Ostling, "Fabrication of $2700-\mathrm{V} 12-\mathrm{m} \Omega \cdot \mathrm{cm} 2$ Non Ion-Implanted $4 \mathrm{H}-$ SiC BJTs With Common-Emitter Current Gain of 50," IEEE Electron Device Lett., vol. 29, Oct. 2008, pp. 1135-1137.

[18] R. Ghandi, B. Buono, M. Domeij, R. Esteve, A. Schoner, J. Han, S. Dimitrijev, S.A. Reshanov, C.M. Zetterling, and M. Ostling, "Surface-Passivation Effects on the Performance of 4H-SiC BJTs," IEEE Trans. Electron Dev., vol. 58, 2011, p. 259-265.

[19] R. Ghandi, B. Buono, M. Domeij, C.-M. Zetterling, and M. Östling, "High Voltage $(2.8 \mathrm{kV})$ Implantation-free 4H-SiC BJTs with Long-Term Stability of the Current Gain," in press, IEEE Trans. Electron Dev., 2011.

[20] M.S. A. Horiuchi, Y. Negoro, K. Iwanaga, S. Yokoyama, H. Hashimoto, M. Sato, Y. Maeyama and K.N. , H. Iwakuro, "No Title," Materials Science Forum, vol. 615-617, 2009, pp. 821-824.

[21] J. Zhang, L. Fursin, X. Li, X. Wang, J.H. Zhao, B.L. VanMil, R. L.M-Ward, J.C.R. Eddy, and D.K. Gaskill, "4H-SiC Bipolar Junction Transistors with Graded Base Doping Profile," Materials Science Forum, vol. 615-617, 2009, pp. 829-832.

[22] B.G. C. Cappel, A. Burk, Q. Zhang, R. Callanan, A. Agarwal and C.J. C Scozzie, "No Title," Journal of Electron Materials, vol. 37, 2008, pp. 662-665.
[23] H.-S. Lee, M. Domeij, C.-M. Zetterling, M. Ostling, F. Allerstam, and E.O. Sveinbjornsson, " $1200-\mathrm{V} 5.2 \mathrm{~m} \Omega \cdot \mathrm{cm} 24 \mathrm{H}-$ SiC BJTs With a High Common-Emitter Current Gain," Electron Device Letters, IEEE, vol. 28, 2007, pp. 1007-1009.

[24] J. Zhang, P. Alexandrov, and J.H. Zhao, "1600 V $5.1 \mathrm{~m} \Omega \cdot \mathrm{cm} 24 \mathrm{H}-\mathrm{SiC}$ BJT with a record high current gain of $\beta=70$," Materials Science Forum, vol. 600-603, 2009, pp. 11551158.

[25] Q. Zhang, A. Burk, F. Husna, R. Callanan, A. Agarwal, J. Palmour, R. Stahlbush, and C.

Scozzie, "4H-SiC bipolar junction transistors: From research to development - A case study: $1200 \mathrm{~V}, 20 \mathrm{~A}$, stable SiC BJTs with high blocking yield," Proceedings of the International Symposium on Power Semiconductor Devices and ICs, ISPSD 2009, pp. 339-342.

[26] S. Balachandran, C. Li, P.A. Losee, I.B. Bhat, and T.P. Chow, " $6 \mathrm{kV} 4 \mathrm{H}-\mathrm{SiC}$ BJTs with specific on-resistance below the unipolar limit using a selectively grown base contact process," Proceedings of the International Symposium on Power Semiconductor Devices and ICs, 2007, pp. 293-296.

[27] J. Zhang, J.H. Zhao, P. Alexandrov, and T. Burke, "Demonstration of first $9.2 \mathrm{kV} 4 \mathrm{H}-\mathrm{SiC}$ bipolar junction transistor," Electronics Letters, vol. 40, 2004, pp. 1381-1383.

[28] P.G. Muzykov, R.M. Kennedy, Q. Zhang, C. Capell, A. Burk, A. Agarwal, and T.S. Sudarshan, "Physical phenomena affecting performance and reliability of $4 \mathrm{H}-\mathrm{SiC}$ bipolar junction transistors," Microelectronics Reliability, vol. 49, 2009, pp. 32-37.

[29] Y. Luo, J. Zhang, P. Alexandrov, L. Fursin, and J.H. Zhao, "Fabrication and characterization of high current gain $($ beta $=430)$ and high power $(23 \mathrm{~A}-500 \mathrm{~V}) 4 \mathrm{H}-$ SiC hybrid Darlington bipolar transistor," IEEE Trans.Electron Dev., vol. 51, 2004, pp. 2211-2216.

[30] Q. Zhang, R. Callanan, A. Agarwal, A. Burk, M. O'Loughlin, J. Palmour, and C. Scozzie, "10 kV, 10 A Bipolar Junction Transistors and Darlington Transistors on 4H-SiC"," Materials Science Forum, vol. 645-648, 2010, pp. 1025-1028. 
[31] Q. Zhang, C. Jonas, M. O Loughlin, R. Callanan, A. Agarwal, and C. Scozzie, "A 10$\mathrm{kV}$ Monolithic Darlington Transistor With of 336 in 4H-SiC," IEEE Electron Device Lett., vol. 30, 2009, pp. 142-144.

[32] R. Ghandi, B. Buono, M. Domeij, and M. Östling, "High Current-Gain ImplantationFree 4H-SiC Monolithic Darlington Transistor," IEEE Electron Device Lett., vol. 32, 2011, p. 188-190.

[33] M. Östling, R. Ghandi, and C.-M. Zetterling, "SiC power devices - present status, applications and future perspective," Proceedings of the 23rd International Symposium on Power Semiconductor Devices \& IC's May 23-26, 2011 San Diego, CA, 2011, pp. 10-15.

[34] Q. Zhang, R. Callanan, M. Das, S.H. Ryu, A.K. Agarwal, and J.W. Palmour, "SiC Power Devices for Microgrids," IEEE Trans. Power Electronics, , vol. 25, 2010, p. 2889-2896.

[35] M.K. Das, J. Zhang, R. Callahan, C. Capell, J. Clayton, M. Donofrio, S.K. Haney, F. Husna, C. Jonas, J. Richmond, and J.J. Sumakeris, "A $13 \mathrm{kV}$ 4H-SiC n-Channel IGBT with Low $\mathrm{R}_{\text {diff,on }}$ and Fast Switching," Materials Science Forum, vol. 600-603, 2009, pp. 1183-1186.

[36] H. O'Brien, A. Ogunniyi, Q. Zhang, and A. Agarwal, "Pulse Performance and Reliability Analysis of a $1.0 \mathrm{~cm} 24 \mathrm{H}-\mathrm{SiC}$ GTO," MRS Proceedings, vol. 1246, 2010, pp. B08-03.

[37] S. Singh and J.A. Cooper, "Bipolar Integrated Circuits in 4H-SiC," IEEE Trans. Electron Dev., vol. 58, 2011, p. 1084-1090.

[38] C.-M. Zetterling, L. Lanni, R. Ghandi, B. G. Malm, and M. Östling, "Future high temperature applications for $\mathrm{SiC}$ integrated circuits", 16th Semiconducting and Insulating Materials Conference (SIMC-XVI), 2011 